\title{
The Inhibition of Imidazoline Type Inhibitor against Pitting Corrosion in Oil Gas Pipes
}

\author{
Lajun Feng ${ }^{1 *}$, Shanjian $\mathrm{Li}^{1}{ }^{2}$, Zhai Zhe ${ }^{1}$, Jing Zhang ${ }^{1}$, Bo Deng ${ }^{1}$, and Ali lei ${ }^{1}$
}

\begin{abstract}
The pitting inhibition of an imidazoline against pitting corrosion in N80 oil pipe was investigated using simulated occluded cell (OC), chemical analysis and potentiodynamic polarization. The results showed that the $\mathrm{pH}$ and inhibition efficiency ( $\eta \%$ value) in the OC increased, Cl- and S2- concentrations in the OC decreased with the increase in inhibitor concentration, and $\eta \%$ value reached the maximum above $95 \%$ at $0.3 \sim 0.4 \mathrm{wt} \%$ inhibitor addition in the bulk solution at $55{ }^{\circ} \mathrm{C}$. The $\mathrm{pH}$ and $\eta \%$ value decreased and $\mathrm{Cl}-$ and S2- concentrations increased slightly with rise in temperature at 0.4 wt \% inhibitor addition.
\end{abstract}

Keywords - Pitting corrosion; N80 steel; Polarization; EIS .

\section{INTRODUCTION}

N80 steel is the most commonly used construction material for pipelines in the oil and gas industry. However, they are very susceptible to corrosion in environment containing $\mathrm{H}_{2} \mathrm{~S}$ and $\mathrm{NaCl}$ [1]. Corrosion of pipes caused by $\mathrm{H}_{2} \mathrm{~S}$ and $\mathrm{Cl}^{-}$is a significant problem in the oil and gas production and transportation systems in China as the continuous oil and gas exploration leads to higher and higher concentrations of $\mathrm{H}_{2} \mathrm{~S}$ and $\mathrm{NaCl}$ in oil and gas in recent decades, which causes costly economic losses due to frequent replacement of oil pipelines to ensure production safety [2]. Imidazoline-based inhibitors have been widely used for protecting carbon steels in acidic environment. The inhibiting efficiency and the mechanism of imidazoline-based inhibitors for carbon steels has been investigated. And the midazoline inhibitors shows a good inhibiting effect on metals in $\mathrm{H}_{2} \mathrm{~S}$ and $\mathrm{Cl}^{-}$coexisting medium [3]. However, so much effort has been taken on the globally corrosion inhibition and adsorption behavior of imidazolinebased inhibitors on carbon steels, none of these investigations have involved the inhibiting effect as well as efficiency of imidazoline-based inhibitors against pitting corrosion in $\mathrm{H}_{2} \mathrm{~S}$ and $\mathrm{Cl}^{-}$coexisting medium.

Therefore, the aim of this work is to explore the inhibiting effect and efficiency of a synthesized imidazoline derivative against pitting corrosion in $\mathrm{N} 80$ oil pipe in $\mathrm{H}_{2} \mathrm{~S}$ and $\mathrm{NaCl}$ coexisting medium, which can provide the theoretical basis for pitting corrosion and protection for pipelines in oil and gas production. For experimental condition the pitting corrosion was s imulated using simulated occluded cell (OC) method

\footnotetext{
${ }^{1}$ School of Materials Science and Engineering, Xi'an University of technology, China.

${ }^{2}$ Country School of Chemistry and Chemical Engineering, Xi'an Shiyou University, China
}

[4], subsequently, the $\mathrm{pH}$ value, $\mathrm{Cl}^{-}$and $\mathrm{S}^{2-}$ concentration as well as electrochemical behaviour of the simulated occluded solution were measured by chemical analysis, potentiodynamic polarization and EIS tequniques, also the corrosion morphology of metals inside the simulated cavity was observed by SEM.

\section{EXPERIMENTAL METHODS}

\section{A. Simulated Occluded Cell (OC) Corrosion}

The pitting corrosion in this work was simulated using a simulated occluded cell (OC) with constant current [5], 1 $\mathrm{mA} / \mathrm{cm}^{2}$, under flowing condition as shown in Fig.1. The OC made of a durable glass tube (Fig.1 (7)) with effective volume around $5 \mathrm{ml}$ was fixed in the middle of the glass tank (Fig.1 (2)). A glass tube at the bottom of the OC with inner diameter $1.5 \mathrm{~mm}$ and length $15 \mathrm{~mm}$ was filled with filter paper scraps, where the difficult diffusion of the corrosion medium through the microporous of filter paper occurs and lead to an occluded state. The prepared corrosion medium with volume $500 \mathrm{ml}$ and $2 \mathrm{ml}$ was filled into the glass tank and OC respectively, and the heights of the bulk and occluded solution were kept the same in all experiments. The occluded specimen (Fig.1 (5)) was plugged into the occluded solution with a rubber stoppers at the top of the durable glass tube, which was connected with the anode while the bulk specimen (Fig.1 (4)) was connected with the cathode of a HDV-7C potentiostat for the purpose of keeping the specimen activity in the $\mathrm{OC}$ according to publication. The current density of the occluded specimen was controlled at $1 \mathrm{~mA} \cdot \mathrm{cm}^{2}$ to simulate the internal and external galvanic current and the occluded specimen works as anode, which is equivalent to the metals inside the cavity when pitting corrosion happens. All of the devices used in the simulated OC were made from materials that would not affect the $\mathrm{pH}$ value of the solution. It is noticed that during inhibitor addition, the inhibitor should be added into the glass tank, i.e., bulk solution (Fig.1 (2)), and keep the occluded solution uninhibited at the start. 


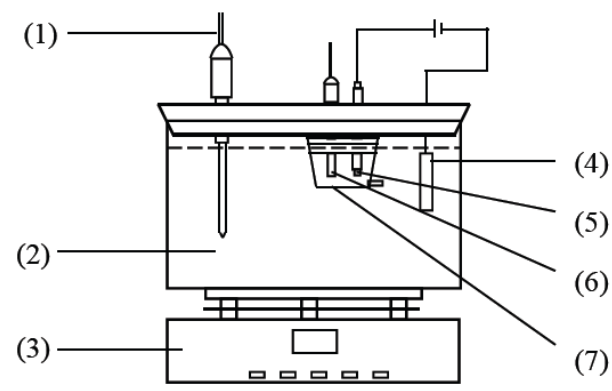

Fig.1 The schematic diagram of simulated occluded cell (1) thermostat; (2) glass tank; (3) magnetic stirrer with heater; (4) bulk specimen; (5) occluded specimen; (6) reference electrode (SCE); (7) occluded cell(OC).

\section{B. Materials and Corrosion Medium}

The material used for the present investigation was special oil pipelines material $\mathrm{N} 80$ steel, with a chemical composition of C:0.42 wt.\%, Si:0.24 wt.\%, Mn:1.55 wt.\%, S:0.004 wt.\%, P:0.012 wt.\%, Cr: 0.051 wt.\%, Mo: 0.18 wt.\%, V0.005 wt.\%, $\mathrm{Ni0.034}$ wt.\%, and $\mathrm{Fe}$ as the balance, was used as a test material. The occluded specimens(Fig.1 (5)) were cut into coupons of dimension $10 \mathrm{~mm} \times 50 \mathrm{~mm} \times 5 \mathrm{~mm}$, which were embedded in epoxy resin with every exposed working area 1 $\mathrm{cm}^{2}$, and the bulk specimens (Fig.1 (4)) were cut into coupons of dimension $25 \mathrm{~mm} \times 40 \mathrm{~mm} \times 10 \mathrm{~mm}$. The effective area ratio of the bulk specimen to the occluded specimen was about 100:1. Prior to each experiment, the exposed surface of the occluded electrode (of area $1 \mathrm{~cm}^{2}$ ) and the bulk electrode (of area100 $\mathrm{cm}^{2}$ ) were polished with a series of silicon carbide papers up to 800 grits, then they were washed with distilled water and degreased in acetone and air dried for standby. The imidazoline quaternary ammonium salt used as inhibitor for this study was prepared in the lab. The standard corrosion medium for corrosion study in oil industry, i.e, $0.5 \%$ $\mathrm{CH}_{3} \mathrm{COOH}+5 \% \mathrm{NaCl}$ solution saturated with $\mathrm{H}_{2} \mathrm{~S}$, was prepared from analar grade chemicals using distilled water, after being deoxygenated by bubbling nitrogen for at least $1 \mathrm{~h}$, the hydrogen sulfide was purged into the solution until it was fully saturated. The initial $\mathrm{pH}$ value of the standard corrosion medium was 4.5.

\section{Analysis of Corrosion}

After $48 \mathrm{~h}$ simulated OC, the OC was taken out of the glass tank. Subsequently, the $\mathrm{pH}$ value, the $\mathrm{Cl}$ - and $\mathrm{S} 2$ concentrations of the occluded solution were measured at room temperature. The $\mathrm{pH}$ values of solutions were determined using pHS-25 pH meter with E-210-C-9 composite electrode. The S2- and $\mathrm{Cl}$ - concentrations were analyzed by iodometry [6] and silver nitrate titration method [7] respectively. $4 \mathrm{ml}$ tetraphenyl boron sodium solution $(7 \mathrm{~g} / \mathrm{L})$ and potassium nitrate solution $(7 \mathrm{~g} / \mathrm{L})$ with the same volume were added into the occluded solution to clear the imidazoline derivative at the beginning before titration.

\section{RESULTS AND DISCUSSION}

\section{A. Effect of Imidazoline Inhibitor on the Chemistry in the OC (Pit)}

Table.1 shows the variations in the $\mathrm{pH}$ values and concentrations of the aggressive ions for the occluded solution after $48 \mathrm{~h}$ simulated $\mathrm{OC}$ at $55^{\circ} \mathrm{C}$ with imposed anodic current density, $1 \mathrm{~mA} / \mathrm{cm}^{2}$, in $\mathrm{H}_{2} \mathrm{~S}$-saturated $5 \% \mathrm{NaCl}+0.5 \%$ $\mathrm{CH}_{3} \mathrm{COOH}$ solutions in absence and presence of the imidazoline inhibitor at various concentrations. It can be seen that in the absence of inhibitor there is an reduction in the $\mathrm{pH}$ value for the occluded solution from initial 4.5 to 3.6 after simulated $\mathrm{OC}$ for $48 \mathrm{~h}$ at $55^{\circ} \mathrm{C}$, this reduction indicates the acidification in the occluded solution. However, in the presence of the imidazoline inhibitor at various concentrations, the $\mathrm{pH}$ value for the occluded solutions increases remarkably when compared with that in the uninhibited solution as the extent of the acidification in the occluded solution decreases. With $0.4 \%$ addition of imidazoline inhibitor in the bulk solution, there is a small decrease in the $\mathrm{pH}$ value of the occluded solution from initial 4.5 to 4.3 after 48 h simulated OC, suggesting that the imidazoline derivative can effectively block the acidification of the occluded solution (the solution in a cavity during pitting corrosion), consequently, the decrease of the $\mathrm{pH}$ value for the occluded solution is retarded to be as slow as possible.

TABLE I: EFFECT OF IMIDAZOLINE INHIBITOR AT VARIOUS CONCENTRATIONS ON THE ChEMISTRY IN THE OCCLUDED SOLUTIONS AT $55^{\circ} \mathrm{C}$

\begin{tabular}{cccccc}
\hline \hline Temperature( $\square)$ & $\mathrm{OC}$ & $\mathrm{C}(\mathrm{wt} \%)$ & $\mathrm{PH}$ & $\mathrm{Cl}^{-}(\mathrm{mol} / \mathrm{L})$ & $\mathrm{S}^{2-}(\mathrm{mol} / \mathrm{L})$ \\
\hline & Before simulated OC & 0 & 4.5 & 0.847 & 0.114 \\
& & 0 & 3.6 & $1.600 \pm 0.002$ & $0.136 \pm 0.003$ \\
55 & & 0.1 & 3.9 & $1.176 \pm 0.001$ & $0.128 \pm 0.005$ \\
& \multirow{3}{*}{ After simulated OC } & 0.2 & 4.1 & $1.058 \pm 0.003$ & $0.122 \pm 0.002$ \\
& & 0.3 & 4.2 & $0.964 \pm 0.002$ & $0.119 \pm 0.001$ \\
& & 0.4 & 4.3 & $0.917 \pm 0.004$ & $0.117 \pm 0.002$ \\
\hline \hline
\end{tabular}

From Table.1, the results reveale that the $\mathrm{pH}$ value of the occluded solution decreases and the $\mathrm{Cl}^{-}$and $\mathrm{S}^{2-}$ concentrations increase remarkably in the absence of inhibitor in the bulk solution, which can be attributed to the corrosion of metals as anode inside the OC (pit), when the dissolution of metal ions in the OC (pit) into the occluded solution occurred, the occluded solution become electropositive due to the enrichment of metal ions in the OC. In order to maintain the occluded solution itself in electric neutrality, the $\mathrm{Cl}^{-}$and $\mathrm{S}^{2-}$ in the bulk solution migrate into the $\mathrm{OC}$ and metal ions in the OC migrate out into the bulk solution, that's the reason for the presence of the multiples of $\mathrm{Cl}^{-}$and $\mathrm{S}^{2-}$ enrichment. Consequently, on the one hand, the enrichment of $\mathrm{Cl}^{-}$can aggravate the possibility for hydrolysis reaction of $\mathrm{FeCl}_{2}$ according to the following equation:

$$
\mathrm{FeCl}_{2}+2 \mathrm{H}_{2} \mathrm{O} \rightarrow \mathrm{Fe}(\mathrm{OH})_{2}+\mathrm{HCl}
$$

From Eq. (1), it is suggested that the occluded solution become more acidic due to the occurrence of hydrolysis reaction of $\mathrm{FeCl}_{2}$, resulting in the decrease in the $\mathrm{pH}$ values, which in return accelerates the dissolution of metals inside the $\mathrm{OC}$ (pit). On the other hand, the presence of $\mathrm{S}^{2-}$ in the 
occluded solution can remarkably reduce the active potential for Fe dissolution in the $\mathrm{OC}$, which also in return accelerates the dissolution of metals inside the OC (pit) [8]. In these cases, the "Autocatalytic Nature" in the OC (within pit) is formed.

It also can be seen from Table. 1 that the concentrations of $\mathrm{Cl}^{-}$and $\mathrm{S}^{2-}$ are enriched to $1.600 \pm 0.002$ and $0.136 \pm 0.003$ $\mathrm{mol} / \mathrm{L}$ respectively in the absence of inhibitor in the bulk solution after $48 \mathrm{~h}$ simulated OC, and that is a 1.89 and 1.19 times enrichment by comparison with that 0.847 and 0.114 $\mathrm{mol} / \mathrm{L}$ of the initial solution before simulated OC. However, in the presence of inhibitor, $\mathrm{Cl}^{-}$and $\mathrm{S}^{2-}$ concentrations in the OC decrease remarkably, especially, with $0.4 \%$ imidazoline addition in the bulk solution, the $\mathrm{Cl}^{-}$and $\mathrm{S}^{2-}$ concentrations reduce nearly 1.74 and 1.16 times respectively when compared to that in the absence of inhibitor. This indicates that imidazoline inhibitor can effectively prevent the corrosion of the occluded metal leading to the decrease of $\mathrm{Fe}^{2+}$ concentration in the $\mathrm{OC}$, as a result, the driving force for $\mathrm{Cl}^{-}$ and $\mathrm{S}^{2-}$ diffusion was decreased. With the decrease in $\mathrm{Cl}^{-}$ concentration in the $\mathrm{OC}$, the hydrolysis reaction of $\mathrm{FeCl}_{2}$ (within OC) is blocked, leading to the retard of the $\mathrm{pH}$ reducing.

Table. 2 shows the variations in the $\mathrm{pH}$ value and concentrations of the aggressive ions for the occluded solution after $48 \mathrm{~h}$ simulated OC with imposed current density, 1 $\mathrm{mA} / \mathrm{cm}^{2}$, in $\mathrm{H}_{2} \mathrm{~S}$-saturated $5 \% \mathrm{NaCl}+0.5 \% \mathrm{CH}_{3} \mathrm{COOH}$ solutions in absence and presence of the imidazoline inhibitor at $25,40,55$ and $70{ }^{\circ} \mathrm{C}$. It can be seen that with the increase in temperature from $25^{\circ} \mathrm{C}$ to $70{ }^{\circ} \mathrm{C}$, the $\mathrm{pH}$ value of the occluded solution decreases from 4.1 to 3.3 , the $\mathrm{Cl}^{-}$and $\mathrm{S}^{2-}$ concentrations increase from $1.341 \pm 0.004$ and $0.120 \pm 0.002$ $\mathrm{mol} / \mathrm{L}$ to $1.670 \pm 0.002$ and $0.140 \pm 0.003 \mathrm{~mol} / \mathrm{L}$ respectively in the absence of inhibitor in the bulk solution after $48 \mathrm{~h}$ simulated $\mathrm{OC}$, suggesting that the $\mathrm{pH}$ value become smaller and the $\mathrm{Cl}^{-}$and $\mathrm{S}^{2-}$ concentrations become higher with the increase in temperature from $25^{\circ} \mathrm{C}$ to $70{ }^{\circ} \mathrm{C}$ in the absence of inhibitor in the bulk solution. However, with $0.4 \%$ imidazoline addition in the bulk solution, the reduction in the $\mathrm{pH}$ value and the increase in the $\mathrm{Cl}^{-}$and $\mathrm{S}^{2-}$ concentrations are slowly. The $\mathrm{pH}$ value remains above 4.2 , and the $\mathrm{Cl}^{-}$and $\mathrm{S}^{2-}$ concentrations remain as low as $0.941 \pm 0.001$ and $0.119 \pm 0.004$ $\mathrm{mol} / \mathrm{L}$ respectively, suggesting that the imidazoline inhibitor can effectively block the acidification and the enrichment of the aggressive ions in the occluded solution at 25, 40, 55 and $70{ }^{\circ} \mathrm{C}$. Generally, with the increase in temperature, the dissolution of the anodic metals, i.e, the corrosion rate within the pit during pitting corrosion increases, meanwhile, the solution viscosity decreases [9] resulting in the increase in the passing rate of the imidazoline molecules into the OC, which can benefit the process of the imidzoline molecules passing from the bulk solution into the occluded solution, but because the desorption of the imidazoline molecules adsorbed on the steel surface in the OC tend to be promoted by the increase of the temperature $[10,11]$, the variation of the $\mathrm{pH}$ value as well as the $\mathrm{Cl}^{-}$and $\mathrm{S}^{2-}$ concentrations are not remarkable.
TABLE II: EFFECT OF TEMPERATURE ON THE CHEMISTRY IN THE OCCLUDED SOLUTIONS IN ABSENCE AND PRESENCE OF $0.4 \%$ IMIDAZOLINE INHIBITOR IN THE BULK SOLUTION

\begin{tabular}{cccccc}
\hline \hline $\mathrm{i}\left(\mathrm{mA} / \mathrm{cm}^{2}\right)$ & $\mathrm{C}(\mathrm{wt} \%)$ & $\mathrm{T}\left({ }^{\circ} \mathrm{C}\right)$ & $\mathrm{pH}$ & $\mathrm{Cl}^{-}(\mathrm{mol} / \mathrm{L})$ & $\mathrm{S}^{2-}(\mathrm{mol} / \mathrm{L})$ \\
\hline & 25 & 4.1 & $1.341 \pm 0.004$ & $0.120 \pm 0.002$ \\
& & 40 & 3.9 & $1.482 \pm 0.001$ & $0.130 \pm 0.002$ \\
& 0 & 55 & 3.6 & $1.600 \pm 0.005$ & $0.136 \pm 0.005$ \\
1 & & 70 & 3.3 & $1.670 \pm 0.003$ & $0.140 \pm 0.004$ \\
& & 25 & 4.5 & $0.870 \pm 0.004$ & $0.115 \pm 0.003$ \\
& \multirow{3}{*}{0.4} & 40 & 4.4 & $0.905 \pm 0.003$ & $0.116 \pm 0.005$ \\
& & 55 & 4.3 & $0.917 \pm 0.001$ & $0.117 \pm 0.002$ \\
& & 70 & 4.2 & $0.941 \pm 0.001$ & $0.119 \pm 0.004$ \\
\hline \hline
\end{tabular}

\section{B. Potentiodynamic Polarization Analysis}

Fig. 2 shows the polarization curves for $\mathrm{N} 80$ steel in the OC (pit) in $\mathrm{H}_{2} \mathrm{~S}$-saturated $5 \% \mathrm{NaCl}+0.5 \% \mathrm{CH}_{3} \mathrm{COOH}$ solutions in absence and presence of the imidazoline inhibitor at various concentrations after $48 \mathrm{~h}$ simulated $\mathrm{OC}$ at $55^{\circ} \mathrm{C}$. It is observed that in the presence of inhibitor in the bulk solution, the curves are shifted to more positive potential as well as lower current region, and the shifts are found dependent on concentration of the inhibitor. Electrochemical corrosion kinetics parameters such as corrosion potential $\left(\mathrm{E}_{\text {corr }}\right)$ and corrosion current density $\left(\mathrm{I}_{\text {corr }}\right)$ obtained by extrapolation of Tafel lines in Fig.2, as well as inhibitor efficiency, $\eta \%$, are listed in Table.3.Theoretically, the inhibition efficiency is defined as:

$$
\eta \%=\left(I_{\text {corr }}^{0}-I_{\text {corr }}\right) / I_{\text {corr }}^{0} \times 100 \%
$$

where $\mathrm{I}_{\text {corr }}^{0}$ and $\mathrm{I}_{\text {corr }}$ are corrosion current densities in solutions without and with inhibitor, respectively, determined by extrapolation of Tafel lines to the corrosion potential.

TABLE III: POTENTIODYNAMIC POLARIZATION PARAMETERS FOR N80 STEEL IN THE OC(PIT) IN H2S-SATURATED $5 \% \mathrm{NACL}+0.5 \% \mathrm{CH} 3 \mathrm{COOH}$

SOLUTIONS IN ABSENCE AND PRESENCE OF IMIDAZOLINE INHIBITOR AFTER $48 \mathrm{H}$ SIMULATED (OCC) AT $25 \sim 70^{\circ} \mathrm{C}$

\begin{tabular}{ccccc}
\hline \multirow{2}{*}{$\mathrm{T}\left({ }^{\circ} \mathrm{C}\right)$} & $\mathrm{C}$ & $(w t \%)$ & \multicolumn{3}{c}{ Polarization method } \\
\cline { 3 - 5 } & & $\mathrm{E}_{\text {corr }}(\mathrm{mv})$ & $\mathrm{I}_{\text {corr }}\left(\mu A / \mathrm{cm}^{2}\right)$ & $\eta / \%$ \\
\hline \multirow{2}{*}{25} & 0 & -635.93 & 182.31 & -- \\
& 0.4 & -584.30 & 3.01 & 98.34 \\
40 & 0 & -685.04 & 304.92 & -- \\
& 0.4 & -595.92 & 7.36 & 97.59 \\
& 0 & -739.25 & 374.42 & -- \\
& 0.1 & -646.11 & 39.11 & 89.55 \\
55 & 0.2 & -639.40 & 26.44 & 92.93 \\
& 0.3 & -627.80 & 17.68 & 95.27 \\
& 0.4 & -608.04 & 16.42 & 95.61 \\
& 0 & $-786 . .62$ & 1014.40 & -- \\
70 & 0.4 & -619.23 & 79.25 & 92.19 \\
\hline \hline
\end{tabular}

From Table.3, these results revealed that the corrosion current densities ( $\mathrm{I}_{\text {corr }}$ ) of the curves in the OC (pit) in the presence of imidazoline inhibitor in the bulk solution at $55{ }^{\circ} \mathrm{C}$ are far smaller than that in the OC (pit) in the absence of imidazoline inhibitor. The $\mathrm{I}_{\text {corr }}$ in the OC decreases remarkably 
with the increasing inhibitor concentrations, leading to the increase of inhibition efficiency. $\eta \%$ value of the imidazoline in the $\mathrm{OC}$ is $95.27 \%$ when $0.3 \%$ inhibitor was added into the bulk solution, and the $\eta \%$ value reaches $95.61 \%$ when continuously increase the concentration of the inhibitor in the bulk solution to $0.4 \%$, suggesting that the imidazoline inhibitor can effectively decrease the corrosivity of the occluded solution or even retard the OC (pitting corrosion) when $0.3 \% \sim 0.4 \%$ imidazoline inhibitor is added in $\mathrm{H}_{2} \mathrm{~S}$ saturated $5 \% \mathrm{NaCl}+0.5 \% \mathrm{CH}_{3} \mathrm{COOH}$ solutions.

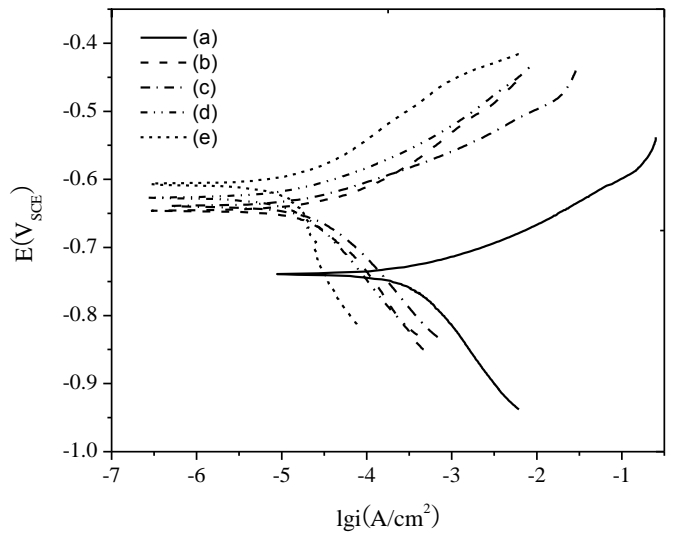

Fig.2: Polarization curves for $\mathrm{N} 80$ steel in the $\mathrm{OC}$ in $\mathrm{H}_{2} \mathrm{~S}$-saturated $5 \% \mathrm{NaCl}+0.5 \% \mathrm{CH}_{3} \mathrm{COOH}$ solutions in absence and presence of imidazoline inhibitor at various concentrations after $48 \mathrm{~h}$ simulated

$\mathrm{OCC}$ at $55^{\circ} \mathrm{C}$ : (a) $0 \%$; (b) $0.1 \%$; (c) $0.2 \%$; (d) $0.3 \%$; (e) $0.4 \%$

\section{CONCLUSIONS}

(1) The imidazoline inhibitor exhibites good inhibition against pitting corrosion in $\mathrm{N} 80$ steel in $\mathrm{H}_{2} \mathrm{~S}$-saturated $5 \% \mathrm{Na} \mathrm{Cl}$ $+0.5 \% \mathrm{CH}_{3} \mathrm{COOH}$ solutions, which can effectively increase the $\mathrm{pH}$ values of the occluded solutions and retard the migration of $\mathrm{Cl}^{-}$and $\mathrm{S}^{2-}$ into the occluded solution at $55^{\circ} \mathrm{C}$, thus, remarkably decrease the multiples of $\mathrm{Cl}^{-}$and $\mathrm{S}^{2-}$ enrichment. Also, the $\mathrm{pH}$ value increases, $\mathrm{Cl}^{-}$and $\mathrm{S}^{2-}$ concentrations in the OC decrease and $\eta \%$ value in the $\mathrm{OC}$ increases with the increase in inhibitor concentrations in the bulk solution, and $\eta \%$ value reachs the maximum above $95 \%$.

(2) With the increase in temperature from $25{ }^{\circ} \mathrm{C}$ to $70{ }^{\circ} \mathrm{C}$, the $\mathrm{pH}$ value of the occluded solution decreases from 4.1 to $3.3, \mathrm{Cl}^{-}$and $\mathrm{S}^{2-}$ concentrations increase from $1.341 \pm 0.004$ and $0.120 \pm 0.002 \mathrm{~mol} / \mathrm{L}$ to $1.670 \pm 0.003$ and $0.140 \pm 0.004$ $\mathrm{mol} / \mathrm{L}$ respectively in the absence of inhibitor in the bulk solution after $48 \mathrm{~h}$ simulated $\mathrm{OC}$ corrosion. The imidazoline also exhibited good pitting inhibition for $\mathrm{N} 80$ steel in $\mathrm{H}_{2} \mathrm{~S}$-saturated $5 \% \mathrm{NaCl}+0.5 \% \mathrm{CH}_{3} \mathrm{COOH}$ solutions at $25 \sim 70{ }^{\circ} \mathrm{C}, \eta \%$ value in the $\mathrm{OC}$ (pit) can still remain above $92 \%$ at $70{ }^{\circ} \mathrm{C}$.

\section{ACKNOWLEDGEMENTS}

This work was financially Supported by the integrated project of Science and Technology of Shaanxi Province China (2014SZS09-K03, 2012KTCG04-1); Excellent Doctor Degree Dissertation Research Foundation of Xi'an University of Technology

\section{REFERENCES}

[1] L. Y. Xiao and W. H. Qiao. "Development of Imidazoline Corrosion Inhibitor for Corrosive Media", Corrosion Science and Protection Technology, vol. 21, pp. 397-400, August 2009.

[2] ASM Handbook: Corrosion ASM Internacional, 2007 Vol. 13, Chapter 10, The Materials Information Society.

[3] P. C. Okafor, X. Liu and Y. G. Zheng. "Corrosion inhibition of mild steel by ethylamino imidazoline derivative in $\mathrm{CO}_{2}$-saturated solution", Corrosion Science, vol. 51, pp. 761-768, April 2009. http://dx.doi.org/10.1016/j.corsci.2009.01.017

[4] C. C. Xu, X. P. Fu, and Y. P. Liu. "Migration of Bariou Inorganic Anions and Their Effects on Occluded Corrosion Cell", Corrosion Science and Protection Technology, vol. 12, pp. 130-137, May 2000.

[5] W. Z. Ouyang, C. C. Xu and L. J. Yue. "On chemical states within occluded cell of rusted cast iron in chloride solution", Journal of Beijing University of Chemical Technology, vol. 31, pp. 51-59, September 2004.

[6] GB/T223.68-1997, Water Quality-Determination of Sulfieds-Idometric Method.

[7] GB/T 15453-95, Industrial Circulation Cooling Water-Determination of Chloride-Silver Nitrate Titration Method.

[8] F. P. Wang, W. L. Kang, and H. M. Jing. Electrochemical Corrosion Principle and Its Aplication. Beijing, China.:Chemical Industry Press.

[9] X. Liu and Y. G. Zhen. "Inhibition Behavior of Two Imidazoline-Based Inhibitors with Different Hydrophilic Groups in Single Liquid Phase and Liquid/Particle Two-Phase Flow", Acta Physico-Chimica Sinica, vol. 25, pp. 713-718, April 2009.

[10] B. Wang, M. Du and J. Zhang. "Inhibition Performance of an Imidazoline Derivative as a Gas-Liquid Two-Phase Inhibitor for Q235 Steel against $\mathrm{CO}_{2}$ Corrosion", Acta Physico-Chimica Sinica, vol. 27, pp. 120-126, January 2011.

[11] Q. He, S. T. Zhang and W. H. Li, et al. "Adsorption Behaviour of New Triazole Derivative as Inhibitor on Mild Steel in Acid Medium", Corrosion and Protection, vol. 29, pp. 243-246, May 2008 